\title{
COMPARISON OF ACETAMINOPHEN AND NALBUPHINE IN ATTENUATING HEMODYNAMIC RESPONSE TO TRACHEAL INTUBATION.
}

1. MBBS, MCPS, FCPS Associate Professor Anaesthesia, Fauji Foundation Hospital, Rawalpindi.

2. MBBS, FCPS

Registrar Anaesthesia, Fauji Foundation Hospital, Rawalpindi.

3. MBBS

Registrar Anaesthesia Fauji Foundation Hospital, Rawalpindi.

4. MBBS, FCPS Professor Surgery Fauji Foundation Hospital, Rawalpindi.

Correspondence Address: Brig (r) Dr Manzoor Ahmad Faridi Department of Anesthesiology

FUMC, Rawalpindi.

faridi548@gmail.com

Article received on: 09/07/2019

Accepted for publication: $13 / 09 / 2019$

\begin{abstract}
Manzoor Ahmad Faridi ${ }^{1}$, Sohail Nasir ${ }^{2}$, Imran Haider ${ }^{3}$, Inamullah Shah ${ }^{4}$
\end{abstract}
ABSTRACT: Laryngoscopy and tracheal intubation cause sympathetic overactivity in the form of increased heart rate and blood pressure, which may lead to deleterious effects. Objectives: The objective of this study was to compare the efficacy of acetaminophen and nalbuphine in attenuating hemodynamic response during tracheal intubation. Study Design: Randomized, double-blind clinical trial. Setting: Main operation theatre complex of Fauji Foundation Hospital Rawalpindi. Period: From August to December 2018. Material \& Methods: After obtaining permission from the institutional ethical review committee of Fauji Foundation Hospital Rawalpindi. 60 Patients of ASA physical status I and II, aged 30 to 55 years, undergoing the abdominal surgical procedure of 1 to 3 -hour duration were randomly divided into two groups. Patients in group $\mathrm{N}$ received nalbuphine hydrochloride $0.15 \mathrm{mg} / \mathrm{kg}$ body weight intravenously, 30 minutes before induction. Patients in group P received acetaminophen infusion (paracetamol) $15 \mathrm{mg} / \mathrm{kg}$ body weight intravenously, 30 minutes before induction. Systolic and diastolic blood pressures were measured manually and heart rate by the pulse oximeter. Observations were made before giving analgesics, during induction, 1 minute after intubation, then at every 1 - minute intervals till first 5 minutes, and thereafter at 10 minutes and at 15 minutes after intubation. The descriptive statistics of data were expressed as mean and standard deviation. Independent samples t-test was used for comparison of mean values of the variables in both groups. The value of $p<0.05$ was considered as statistically significant. Results: There was a significant rise in heart rate and blood pressure after laryngoscopy and endotracheal intubation with acetaminophen $(P$ group) as compared to the $\mathrm{N}$ group in which nalbuphine effectively reduced the tachycardia and hypertension. Conclusion: Acetaminophen has no significant effect on the prevention of hemodynamic changes due to intubation. Nalbuphine effectively reduces tachycardia and hypertension associated with laryngoscopy and endotracheal intubation.

Key words: Acetaminophen, Intubation Response, Nalbuphine, Tracheal Intubation

Article Citation: Faridi MA, Nasir S, Haider I, Shah I. Comparison of acetaminophen and nalbuphine in attenuating hemodynamic response to tracheal intubation. Professional Med J 2020; 27(2):341-347.

DOI: 10.29309/TPMJ/2020.27.2.3921

\section{INTRODUCTION}

Laryngoscopy and orotracheal intubation can be associated with significant hemodynamic changes and adverse outcomes. ${ }^{1}$ Various drugs like fentanyl, lignocaine etc. have been tried to prevent hemodynamic changes but each drug has its own limitations. ${ }^{2,3}$

Opioids are important drugs in the management of attenuation of hemodynamic response during intubation. Use of opioids before induction of general anesthesia makes the intraoperative course smooth and decreases the intraoperative requirement of anesthetic agents. ${ }^{4}$
Nalbuphine, an ideal analgesic for use in balanced anesthesia because of its beneficial effects on cardiovascular stability and potential safety in over-dosage, which causes adverse effects like nausea, vomiting and at times respiratory depression. ${ }^{5,6}$

Acetaminophen (Paracetamol) has been successfully used for management of postoperative pain in different types of operations. ${ }^{7,8}$

Studies conducted in the past to assess the efficacy of acetaminophen in attenuating the 
hemodynamic presser response $\mathrm{e}^{9,10}$ found it to be efficacious. Acetaminophen has also been compared with local anesthetic agents like lidocaine. ${ }^{11}$ but the literature search did not yield any comparison with the widely used opioid analgesics like nalbuphine.

Most opioid drugs like morphine, fentanyl and remifentanilare are not available in the majority of the hospitals of our country whereas nalbuphine and acetaminophen are easily available. Acetaminophen, a non-opioid analgesic, does not cause adverse effects associated with opioids such as respiratory depression, nausea and vomiting. ${ }^{7,8}$ Also, it has few contraindications and no significant drug interactions. ${ }^{12}$

Keeping in view a better profile of acetaminophen in regard to adverse effects, contraindications, and interactions with other drugs, we wanted to find out if it could be used instead of nalbuphine in attenuating the presser response during orotracheal intubation while administering general anaesthesia. This randomized clinical trial was conducted to compare both drugs with the hypothesis that acetaminophen is as effective in attenuating the hemodynamic response during tracheal intubation as nalbuphine. Variables studied in hemodynamic response were heart rate, systolic and diastolic blood pressure.

The objective of this study was to compare the efficacy of acetaminophen and nalbuphine in attenuating hemodynamic response during tracheal intubation.

\section{MATERIAL AND METHODS}

This was a randomized, double-blind, clinical trial carried out in Fauji Foundation Hospital Rawalpindi over a period of four months from August to November 2018. Permission from the institutional ethical review committee was obtained.

A detailed history was elicited and physical examination performed during pre-anesthesia assessment. Complete blood count, liver function tests, renal function tests, bleeding time, and clotting time were carried outbefore enrolling each patient as a study subject. Patients in American Society of Anesthesiologists (ASA) physical Status I and II, 30 to 55 years of age, of either sex, with weight 40 to $75 \mathrm{~kg}$, undergoing abdominal surgical procedures, with the expected surgical duration of 1 to 3 hours, were included in this study. Patients who were unwilling to participate in the study, patients with difficult intubation, or those with systemic diseases such as severe hypertension, ischemic heart disease, hepatic or renal disorder, patients on tricyclic inhibitors, pregnant and lactating females, those in obese range and those with chronic opioid therapy, and addiction to any drug or alcohol were excluded from the study.

Informed consent was obtained in writing on a structured proforma. Two groups namely Nalbuphine (N) group and Paracetamol (P) group were formed. Sample size calculated by WHO sample size calculator was 30 subjects in each group. Randomization was done by preparing 60 envelopes containing plan of the drug to be used for attenuation of hemodynamic response.

Half of them $(n=30)$ were allocated nalbuphine and the other half $(n=30)$ were allocated Paracetamol (acetaminophen) as the drug to be used. The envelopes were not labeled and one of the envelopes was selected randomly by the anaesthesiologist of the case. The drug was administered by the anaesthesiologist.

Hemodynamic parameters during and after tracheal intubation were recorded by an observer who was blinded to the preparation and administration of the study drug. Patients who received nalbuphine were included in Group N whereas thosewho received acetaminophenwere included in Group P.

Independent variable in this study was the drug - nalbuphine or acetaminophen - used for attenuation of hemodynamic response during tracheal intubation. Dependent variables that were studied in both groups included heart rate, systolic blood pressure and diastolic blood pressure. Demographic variables were also recorded and compared for both groups. These 
included age, gender, weight, ASA grade and duration of surgery in each patient.

After confirming adequate starvation period, all routine monitors including noninvasive blood pressure, pulseoximeter and ECG were attached to the patient. An $18 \mathrm{G}$ intravenous catheter was secured in all patients.

No premedication was given and then according to the randomization, each patient was administered either nalbuphine hydrochloride $0.15 \mathrm{mg} / \mathrm{kg}$ or acetaminophen infusion 15mg/ $\mathrm{kg}$ intravenously 30 minutes before induction. Systolic and diastolic blood pressure and heart rate were noted.

Patients were pre-oxygenated for 5 minutes. Systolic and diastolic blood pressure was noted manually and heart rate by pulse oximeter before giving analgesics. Thirty minutes after administration of analgesic drug, anesthesia was induced with propofol $2 \mathrm{mg} / \mathrm{kg}$ injection in titrated doses. Muscle relaxation was achieved with injection atracurium $0.5 \mathrm{mg} / \mathrm{kg}$ and all patients were manually ventilated with $\mathrm{O}_{2}: \mathrm{N}_{2} \mathrm{O}(50: 50)$ for 3 minutes. Tracheal intubation was done under direct laryngoscopy by anesthesiologist. Systolic and diastolic blood pressure and heart rate were again noted at the time of induction, then at every 1-minute interval after intubation till first 5 minutes, and thereafter at 10 minutes and 15 minutes after intubation.

Anesthesia was maintained with $\mathrm{O}_{2}$ and $\mathrm{N}_{2} \mathrm{O}$, isoflurane, atracurium and intermittent injection propofol so that blood pressure and heart rate should remain within $20 \%$ of baseline value. Injection ketorolac $30 \mathrm{mg}$ was added to enhance the analgesia.

At the end of the surgery, isoflurane was tapered off gradually and after completion of the procedure and resumption of spontaneous respiration, anesthesia was reversed with neostigmine 0.05 $\mathrm{mg} / \mathrm{kg}$ and glycopyrrolate $0.008 \mathrm{mg} / \mathrm{kg}$.

All patients were extubated after they resumed good muscle tone and respiration, their vital parameters noted and then shifted to the postoperative care unit.

The descriptive statistics of data were expressed as mean and standard deviation. Independent samples t-test was used for comparison of mean values of the variables in both groups. The value of $p<0.05$ was considered as statistically significant.

\section{RESULTS}

Groups $\mathrm{N}$ and $\mathrm{P}$ were comparable with respect to age, weight, gender ratio and ASA classification. They were also similar with respect to the type and duration of operative procedures Table-I.

Mean baseline heart rate measured after injecting analgesic drugs was less in $\mathrm{N}$ group as compared to the P group (Table-II).

There was an increase of heart rate after intubation initially in both groups as compared to heart rate taken at time of induction.

However, this was significantly higher $(p=.000)$ with acetaminophen ( $P$ group) and remained significantly high for another 15 minutes as compared to those who received nalbuphine ( $\mathrm{N}$ group) where heart rate remained near baseline.

Table-III shows systolic blood pressure at time of induction and changes after intubation.

There was an increase of systolic blood pressure after intubation initially in both groups, however, this was significantly higher in the group that received acetaminophen and remained significantly high for further 15 minutes as compared to nalbuphine group where systolic blood pressure remained near baseline.

Diastolic blood pressure after intubation showed no rise in $\mathrm{N}$ group but was raised in $\mathrm{P}$ group Table-IV). The difference in means of both groups remained significant over the next 15 minutes $(p \leq .007)$. 


\begin{tabular}{|l|c|c|c|}
\hline \multicolumn{1}{|c|}{ Variables } & Group N Nalbuphine & Group P Acetaminophen & P-Value \\
\hline Age in years (Mean \pm SD) & $43.87 \pm 7.9$ & $42.17 \pm 7.1$ & .385 \\
\hline Gender (Male/Female) & $11 / 19$ & $12 / 18$ \\
\hline Weight in kg (Mean \pm SD) & $61.83 \pm 4.6$ & $60.70 \pm 4.5$ & .341 \\
\hline ASA Grade (I/II) & $23 / 7$ & $25 / 7$ & .374 \\
\hline Duration of surgery (<90 mins / >90 mins) & $16 / 14$ & $18 / 12$ & .397 \\
\hline
\end{tabular}

Table-I. Comparison of basic parameters in each group.

\begin{tabular}{|l|c|c|c|}
\hline \multirow{2}{*}{\multicolumn{1}{|c|}{ Time Interval }} & \multicolumn{2}{|c|}{ Mean Heart Rate \pm SD(bpm) } & P-Value \\
\cline { 2 - 4 } & Group N (n=30) & Group P(n=30) & .433 \\
\hline Before analgesics & $81.27 \pm 7.343$ & $79.07 \pm 13.375$ & .000 \\
\hline During induction(30 min after analgesics) & $72.13 \pm 4.812$ & $87.87 \pm 12.159$ & .000 \\
\hline 1 min after intubation & $75.67 \pm 8.327$ & $93.90 \pm 9.484$ & .000 \\
\hline 2 min after intubation & $76.40 \pm 7.677$ & $98.47 \pm 9.794$ & .000 \\
\hline 3 min after intubation & $73.47 \pm 5.507$ & $102.13 \pm 9.497$ & .000 \\
\hline 4 min after intubation & $70.77 \pm 5.624$ & $101.20 \pm 11.112$ & .000 \\
\hline 5 min after intubation & $70.63 \pm 5.768$ & $102.87 \pm 8.299$ & .000 \\
\hline 10 min after intubation & $69.57 \pm 5.661$ & $105.40 \pm 8.224$ & .000 \\
\hline 15 min after intubation & $69.70 \pm 5.167$ & $107.00 \pm 6.983$ & \\
\hline
\end{tabular}

Table-II. Comparison of mean heart rate in both groups.

\begin{tabular}{|l|c|c|c|}
\hline \multirow{2}{*}{\multicolumn{1}{|c|}{ Time Interval }} & \multicolumn{2}{c|}{ Mean Systolic BP \pm SD(mmHg) } \\
\cline { 2 - 4 } & Group N $(n=30)$ & Group P(n=30) & P-Value \\
\hline Before analgesics & $129.17 \pm 9.105$ & $124.83 \pm 15.227$ & .186 \\
\hline During induction (30 min afteranalgesics) & $119.73 \pm 9.063$ & $127.63 \pm 12.802$ & .008 \\
\hline 1 min after intubation & $122.83 \pm 10.642$ & $131.83 \pm 12.831$ & .004 \\
\hline 2 min after intubation & $124.23 \pm 9.100$ & $136.33 \pm 12.383$ & .000 \\
\hline 3 min after intubation & $119.93 \pm 8.038$ & $132.43 \pm 15.167$ & .000 \\
\hline 4 min after intubation & $119.40 \pm 6.896$ & $132.50 \pm 13.630$ & .000 \\
\hline 5 min after intubation & $119.00 \pm 7.240$ & $131.17 \pm 14.062$ & .000 \\
\hline 10 min after intubation & $118.40 \pm 6.468$ & $133.67 \pm 13.892$ & .000 \\
\hline 15 min after intubation & $116.50 \pm 5.894$ & $136.17 \pm 13.814$ & \\
\hline
\end{tabular}

Table-III: Comparison of means of systolic BP in both groups.

Time Interval

Before analgesics

During induction (30 min after analgesics)

1 min after intubation

2 min after intubation

3 min after intubation

4 min after intubation

5 min after intubation

10 min after intubation

15 min after intubation
Mean Diastolic BP $\pm \mathrm{SD}(\mathrm{mmHg})$

Group N (n=30)

$78.43 \pm 5.823$

$71.03 \pm 5.524$

$76.20 \pm 8.075$

$77.50 \pm 8.460$

$73.13 \pm 6.976$

$73.10 \pm 6.381$

$68.93 \pm 6.767$

$69.40 \pm 5.525$

$69.03 \pm 4.529$
Group $P(n=30)$

$76.97 \pm 10.005$

$80.87 \pm 8.792$

$85.53 \pm 10.494$

$84.17 \pm 9.914$

$84.63 \pm 10.391$

$85.73 \pm 10.174$

$86.57 \pm 11.038$

$87.13 \pm 9.540$

$89.50 \pm 7.847$
P-Value .490 .000 .000 .007 .000 .000 .000 .000

.000

Table-IV. Comparison of means of diastolic BP in both groups. 


\section{DISCUSSION}

Direct laryngoscopy involves stretching the oropharyngeal tissues in an attempt to straighten the angle between the mouth and the glottic opening, and this stretch can cause pain and trigger stress response. ${ }^{13}$ The plasma levels of sympathetic hormones like dopamine, adrenaline and noradrenaline could rise during laryngoscopy and endotracheal intubation. This results in a hemodynamic response that causes complications in high risk patients, leading to increased morbidity and mortality. ${ }^{14}$

In order to blunt the responses to endotracheal intubation, various drugs have been used such as lignocaine and opioids and non-narcotic analgesics. ${ }^{2,3}$ An ideal drug should be easily administered, have a rapid onset of action, relatively short duration of action, and be safe. Ideal drugs include fentanyl and alfentanil but unfortunately these drugs areunavailable in most hospitals in Pakistan. Nalbuphine, on the other hand, is easily available. It acts as an antagonist on $\mu$ receptors and an agonist on ê receptors. Its onset of action is between 2 to 3 minutes and the duration of action is 3 to 6 hours. There are minimal side effects in the dose of $0.2-0.4 \mathrm{mg} /$ $\mathrm{kg}$ and no deleterious effects on cardiovascular stability. ${ }^{4-6}$

Another analgesic drug which is easily available is acetaminophen (paracetamol). Paracetamol has a well-established safety and analgesic profile. ${ }^{15}$ Its main mechanism of action is inhibition of cyclooxygenase enzyme which is responsible for the production of prostaglandins, an important mediator of inflammation, pain and fever. Its maximum recommended dose in adults is 4000 $\mathrm{mg} /$ day. Onset of action is within 5 to 10 minutes of administration and the duration of action is 4 to 6 hours. $^{15}$

In this study we used paracetamol $15 \mathrm{mg} / \mathrm{kg}$ body weight in comparison with nalbuphine0.15 $\mathrm{mg} / \mathrm{kg}$ body weight to observe blunting of the hemodynamic response brought on by intubation. This results of this study show that acetaminophen is significantly less effective in blunting the hemodynamic response as compared to nalbuphine. The hypothesis of this study therefore stands rejected. These findings are contrary to a double-blind, randomized study by Ayatollahi $\mathrm{V}$ et al that showed intravenous acetaminophen to be efficaciousin blunting hemodynamic responses to tracheal intubation in comparison to placebo. ${ }^{9}$

KordValeshabad et $\mathrm{al}^{11}$ in a study proved that paracetamol one hour prior to intubation attenuates heart rate response after laryngoscopy but is not effective to prevent acute alterations in blood pressure after intubation. Results of our study are not in conformity with their findings as we found acetaminophen to be ineffective in controlling hemodynamic response.

Opioid administration is not recommended in parturient patients undergoing cesarean section because of its depressant effects on the newborn. A placebo controlled trial conducted by Soltani G et al on these patients showed that acetaminophen reduced tachycardia in response to endotracheal intubation when used before induction but has no effect on rise in blood pressure. ${ }^{10}$ Our trial partially agrees with this study as it shows no significant blunting in rise of heart rate as well as blood pressure.

Kashif et al, in a study to evaluate the efficacy of intravenous paracetamol in the prevention of hemodynamic changes during intubation, reported that paracetamol probably has no role in preventing hemodynamic alterations due to intubation. ${ }^{16}$ These results compare favorably to those of our study in which administration of intravenous acetaminophen 30 minutes before surgical procedure has no significant effect on preventing hemodynamic changes at the time of endotracheal intubation.

The strength of our study is that it is the first randomized clinical trial to compare acetaminophen with nalbuphine, as an alternate pharmacologic agent to be used for blunting hemodynamic response to endotracheal intubation. We conclusively established that it does not compare in efficacy to nalbuphine for this purpose. The sample size $(n=60)$ is relatively 
small but is sufficient in evaluation of the research question and is comparable with previous studies on the subject. Further studies are recommended to compare other pharmacologic agents with opioids in order to find an effective alternate to opioids for attenuation of pressor response.

\section{CONCLUSION}

Acetaminophen has no significant effect on the prevention of hemodynamic changes due to intubation, as compared to nalbuphine which effectively reduces tachycardia and hypertension. Copyright(C) 13 Sep, 2019.

\section{REFERENCES}

1. Beyer K, Taffe P, Halfon P, Pittet V, Pichard S, Haller G, et al. Hypertension and intra-operative incidents: $A$ multicentre study of 125,000 surgical procedures in Swiss hospitals. Anaesthesia. 2009; 64(5):494-502. [Pubmed]

2. Jalali A, Nasiri E, Khoramian M, Saghafinia M, Siamian $\mathrm{H}$. Hemodynamic responses to tracheal intubation in elderly patients: Intravenous or spray of lidocaine versus fentanyl. Medical archives (Sarajevo, Bosnia and Herzegovina). 2017; 71(6):424-9. [Pubmed]

3. Hashemian AM, Zamani Moghadam Doloo H, Saadatfar M, Moallem R, Moradifar M, Faramarzi R, et al. Effects of intravenous administration of fentanyl and lidocaine on hemodynamic responses following endotracheal intubation. The American journal of emergency medicine. 2018; 36(2):197-201.[Pubmed]

4. Fragen RJ, Caldwell N. Acute intravenous premedication with nalbuphine. Anesthesia and analgesia. 1977; 56(6):808-12.[Pubmed]

5. Klepper ID, Rosen M, Vickers MD, Mapleson WW. Respiratory function following nalbuphine and morphine in anaesthetized man. British journal of anesthesia. 1986; 58(6):625-9.[Pubmed]

6. Lake CL, Duckworth EN, DiFazio CA, Magruder MR. Cardiorespiratory effects of nalbuphine and morphine premedication in adult cardiac surgical patients. Actaanaesthesiologica Scandinavica. 1984; 28(3):305-9. [Pubmed]

7. Majumdar S, Das A, Kundu R, Mukherjee D, Hazra B, Mitra T. Intravenous paracetamol infusion: Superior pain management and earlier discharge from hospital in patients undergoing palliative head-neck cancer surgery. Perspectives in clinical research. 2014; 5(4):172-
8. Shimia $M$, Parish $M$, Abedini $N$. The effect of intravenous paracetamol on postoperative pain after lumbar discectomy. Asian spine journal. 2014; 8(4):400-4. [Pubmed]

9. Ayatollahi V, Faghihi $S$, Behdad $S$, Heiranizadeh $\mathrm{N}$, Baghianimoghadam B. Effect of preoperative administration of intravenous paracetamol during cesarean surgery on hemodynamic variables relative to intubation, postoperative pain and neonatal Apgar. Actaclinica Croatica. 2014; 53(3):272-8. [Pubmed]

10. Soltani G, Molkizadeh A, Amini S. Effect of intravenous acetaminophen (Paracetamol) on hemodynamic parameters following endotracheal tube intubation and postoperative pain in caesarian section surgeries. Anesthesiology and pain medicine. 2015; 5(6):e30062. [Pubmed]

11. KordValeshabad A, Nabavian O, Nourijelyani K, Kord $\mathrm{H}$, Vafainejad $\mathrm{H}$, KordValeshabad $\mathrm{R}$, et al. Attenuation of hemodynamic responses to laryngoscopy and tracheal intubation: Propacetamol versus lidocaine-a randomized clinical trial. Anesthesiology research and practice. 2014; 2014: 170247.[Pubmed]

12. Elbohoty AE, Abd-Elrazek H, Abd-El-Gawad M, Salama F, El-Shorbagy M, Abd-El-Maeboud $\mathrm{KH}$. Intravenous infusion of paracetamol versus intravenous pethidine as an intrapartum analgesic in the first stage of labor. International journal of gynaecology and obstetrics: the official organ of the International Federation of Gynaecology and Obstetrics. 2012; 118(1):7-10.[Pubmed]

13. Kamewad AK, Sharma VK, Kamewad SM, Popli V. Haemodynamic response to endotrachial intubation: direct versus video laryngoscopy. International Journal of Research in Medical Sciences; Vol 4, No 12 (2016): December 2016DO-1018203/2320-6012ijrms20164040. 2016. [IJRMS]

14. Fox EJ, Sklar GS, Hill CH, Villanueva R, King BD. Complications related to the pressor response to endotracheal intubation. Anesthesiology. 1977; 47(6):524-5. [Pubmed]

15. Court MH, Zhu Z, Masse G, Duan SX, James LP, Harmatz JS, et al. Race, gender, and genetic polymorphism contribute to variability in acetaminophen pharmacokinetics, metabolism, and protein-adduct concentrations in healthy African-American and European-American Volunteers. The Journal of pharmacology and experimental therapeutics. 2017; 362(3):431-40. [Pubmed] 
16. Kashif S, Hamid M. Efficacy of intravenous paracetamol on pressor response in patients undergoing cesarean section under general anesthesia. Journal of anesthesiology, clinical pharmacology. 2016; 32(2):210-3. [Pubmed]

\section{AUTHORSHIP AND CONTRIBUTION DECLARATION}

\begin{tabular}{|c|c|c|c|}
\hline Sr. \# & Author(s) Full Name & Contribution to the paper & Author(s) Signature \\
\hline 1 & Manzoor Ahmad Faridi & Major Research work. & \\
\hline 2 & Sohail Nasir & $\begin{array}{l}\text { Helping in research work \& } \\
\text { collection of data. }\end{array}$ & \\
\hline 3 & Imran Haider & $\begin{array}{l}\text { Helping in research work \& } \\
\text { collection of data. }\end{array}$ & \\
\hline 4 & Inamullah Shah & $\begin{array}{l}\text { Helping in research work } \\
\text { and statistical work. }\end{array}$ & \\
\hline
\end{tabular}

